\section{Detailed study of a lateritic cover in NE French Guiana: dynamic evolution through time extracted from mineralogy, geochemistry and geochronology}

\author{
BEATRIX HELLER ${ }^{1,2}$, SILVANA BRESSAN RIFFEL ${ }^{3}$, \\ CÉCILE E GAUTHERON ${ }^{1}$, THIERRY ALLARD ${ }^{2}$, \\ GUILLAUME MORIN ${ }^{2}$, JEAN-YVES ROIG ${ }^{4}$ AND RENAUD \\ COUEFFE $^{4}$ \\ ${ }^{1}$ Université Paris Saclay, CNRS \\ ${ }^{2}$ Sorbonne Université, CNRS \\ ${ }^{3}$ Federal University of Rio Grande do Sul \\ ${ }^{4}$ BRGM
}

Presenting Author: beatrix.heller@universite-paris-saclay.fr

Laterites are deep soils that develop under intense chemical weathering and low physical erosion rates. Despite their large extension at the Earth's surface, there is still a lack of chronological frame for their formation, evolution and relation with climatic change. To add additional temporal constraints on those relationships, we present a detailed study of one lateritic cover in Northeast French Guiana which developed on top of Paleoproterozoic rocks of the Guyana shield, an area known as tectonically stable and in tropical latitudes since the Cretaceous. The study site, Kaw mountain ridge, is a paleosurface at $300 \mathrm{~m}$ elevation that has previously been dated by paleomagnetism, providing an Eocene age albeit with some substantial uncertainty and dispersion [1]. Our sample set consists of surface samples of the iron duricrust and material from a drill core from the top of the ridge. To get an insight into the evolution of the lateritic system through time we combine mineralogical and geochemical analyses with geochronological methods.

The mineralogy of the lateritic profile is rather simple, consisting mainly of secondary minerals such as kaolinite, iron oxyhydroxides and aluminium hydroxides. As the petrological relationship between the different phases, especially in the duricrust, is often very complex due to multiple cycles of dissolution/reprecipitation processes, dating this type of material is very challenging. Goethite and hematite, the main components of the duricrust, can be dated using the (U-Th-Sm)/He method. However, a profound comprehension of the phase relationships is needed to interpret the geochronological results. Coupling of (UTh-Sm)/He dating with Scanning Electron Microscopy and single grain X-ray diffraction allows identification of phases with increased Fe-mineral precipitation. At Kaw, precipitation of $\mathrm{Fe}$ minerals started at least in the Early Oligocene and was intensified during the Middle Miocene and the Plio- and Pleistocene. In detail, the observed structures are often complex and the age results are very dispersed, probably due to extremely humid conditions which lead to simultaneous formation and degradation of the iron duricrust. The present ages complement the paleomagnetism ages, by revealing additional weathering episodes at the Kaw mountain ridge.

[1] Théveniaut \& Freyssinet (2002), Palaeogeography, 